\title{
Capillary Pumping between Droplets on Superhydrophobic Surfaces
}

\author{
shiva moradi ${ }^{1}$, Mohammad Charsooghi $^{1}$, Luca Businaro ${ }^{2}$, Mehdi Habibi $^{3}$, and Ali-Reza \\ Moradi $^{4}$ \\ ${ }^{1}$ Affiliation not available \\ ${ }^{2}$ Institute of Photonics and Nanotechnologies National Research Council \\ ${ }^{3}$ Wageningen Universiteit en Researchcentrum \\ ${ }^{4}$ Institute for Advanced Studies in Basic Sciences
}

November 14, 2021

\begin{abstract}
The famous two-balloon experiment involves two identical balloons filled up with air and connected via a hollow tube, and upon onsetting the experiment one of the balloons shrinks and the other expands. Here, we present the liquid version of that experiment. We use superhydrophobic (SHP) substrates to form spherical droplets and connect them with a capillary channel. Different droplet sizes, substrates of different hydrophobicities, and various channel pathways are investigated, and morphometric parameters of the droplets are measured through image processing. In the case of SHP substrates the pumping is from the smaller droplet to the larger one, similar to the two-balloon experiment. However, if one or both of the droplets are positioned on a normal substrate the curvature radius will indicate the direction of pumping. We interpret the results by considering the Laplace pressures and the surface tension applied by the channel at the connecting points.
\end{abstract}

\section{Hosted file}

AIChE-21-24502_Proof_hi.pdf available at https://authorea.com/users/279200/articles/545441capillary-pumping-between-droplets-on-superhydrophobic-surfaces

\section{Hosted file}

AICHE2021shp_pump_manuscript.tex available at https://authorea.com/users/279200/articles/ 545441-capillary-pumping-between-droplets-on-superhydrophobic-surfaces 

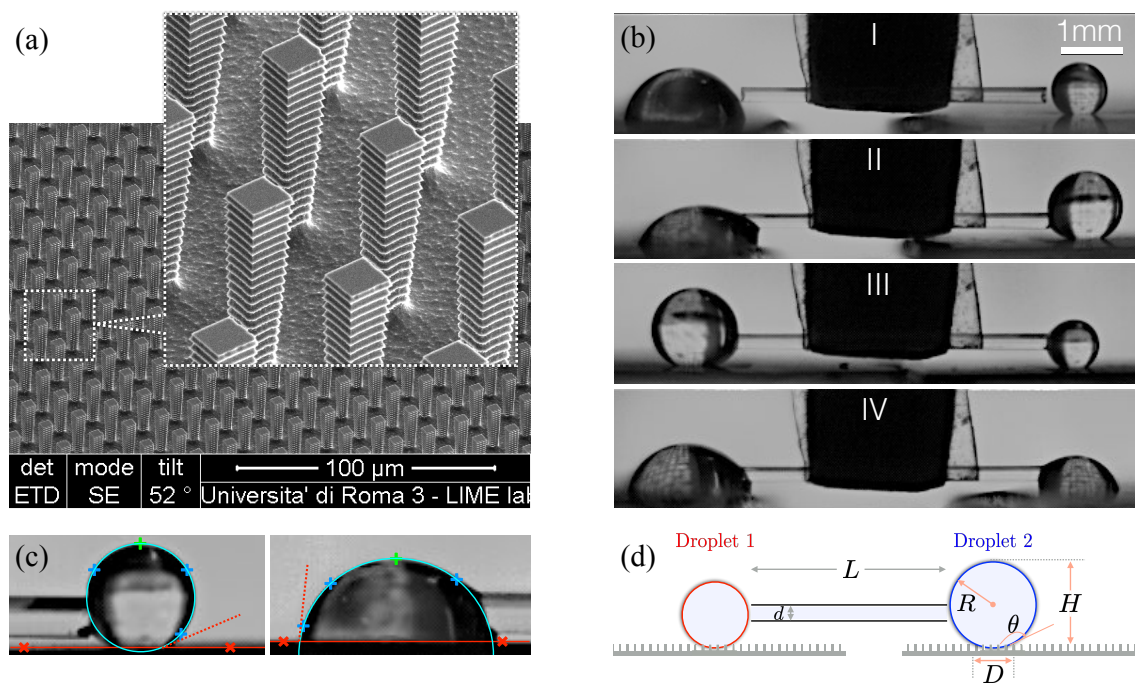

(a)
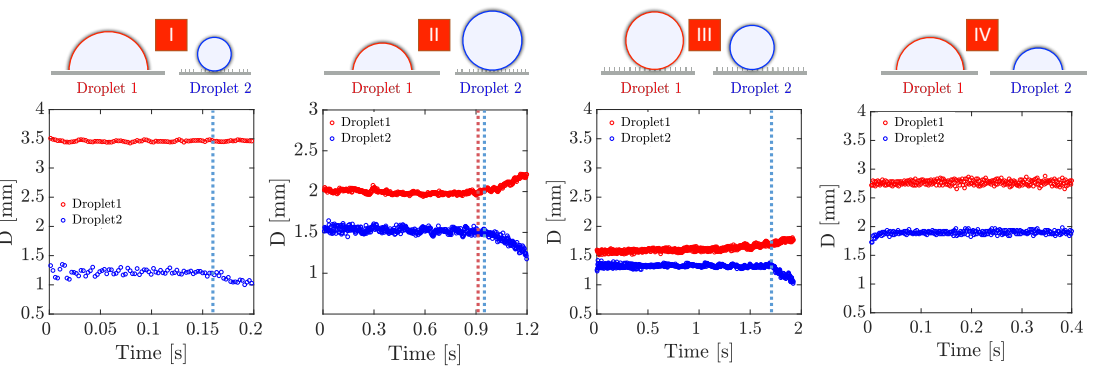

(b)
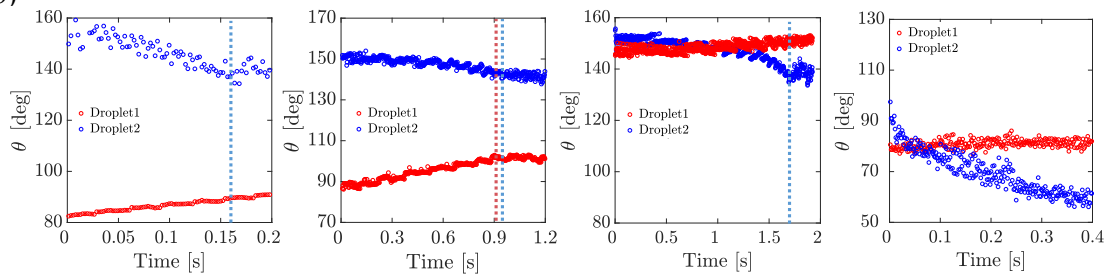
(a)

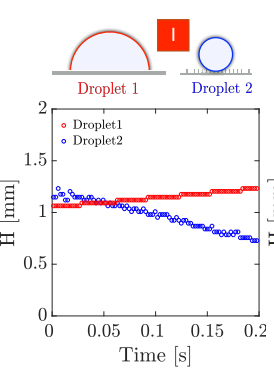

(b)

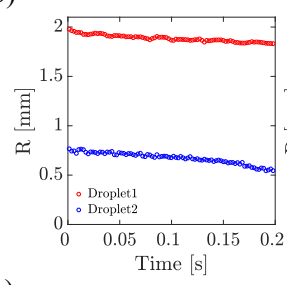

(c)
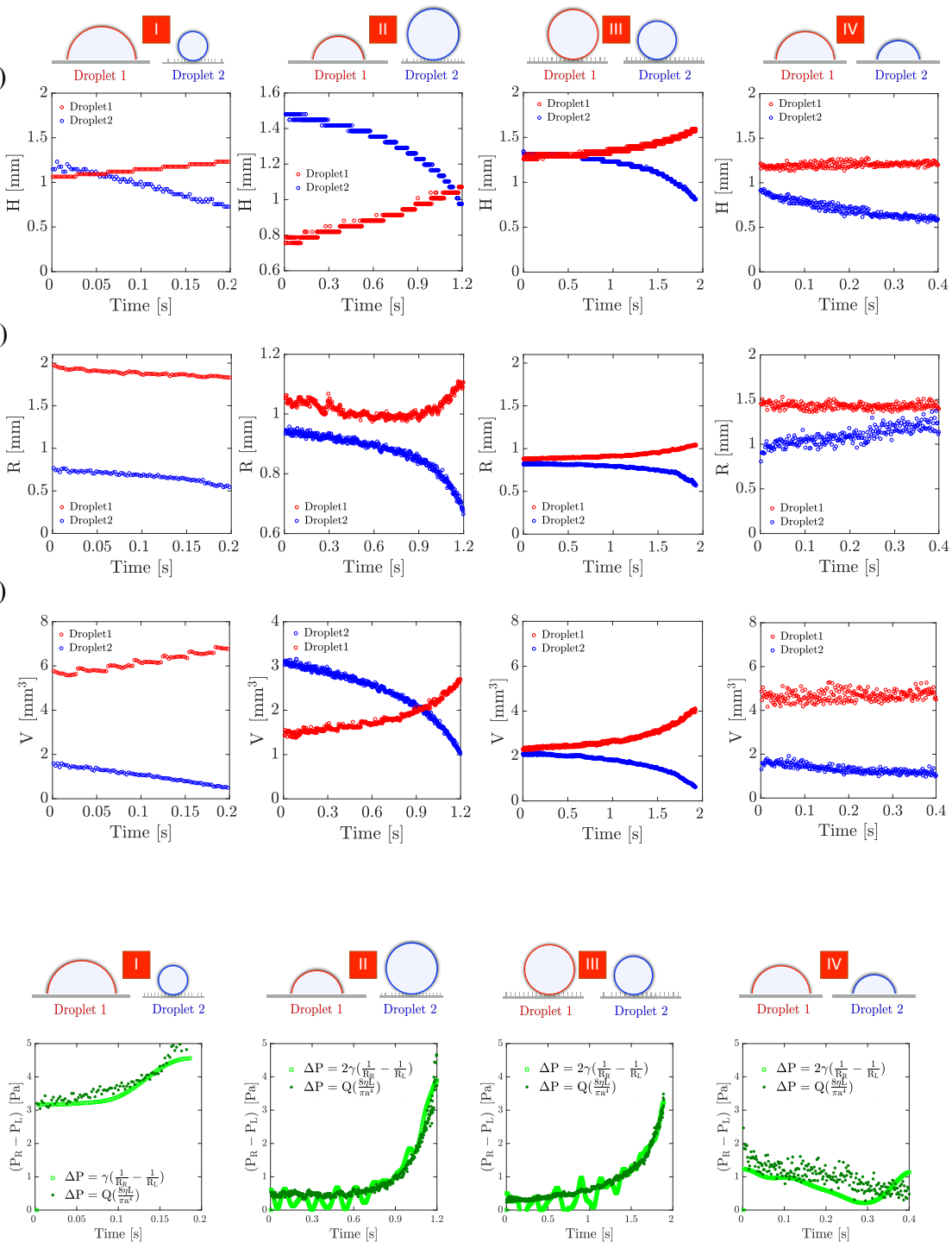